\title{
Clinical audit on quality of post anesthesia extubation in the operation theatres in a specialized university hospital
}

\begin{abstract}
Background: endotracheal extubation is defined as the removal of an endotracheal tube from the trachea. After extubation airway control is equally as important as securing the airway during anesthesia. Successful extubation should be the first priority for the anesthetist through checking the adequacy of breathing, verbal commands, full reversal of muscle relaxants and stabilizing of the vital signs.
\end{abstract}

Aim: the aim of this audit was to evaluate the quality of post anesthesia extubation practices in a specialized teaching hospital.

Materials and methods: this clinical audit was conducted from January 1 to February 30 , 2019 in university of Gondar referral hospital. All patients who were undergoing surgery with general anesthesia in the study period were included. A data collection tools for this clinical audit were prepared based on different literatures recommendations. Statistical analysis: descriptive statistics were performed using SPSS version 20 .

Results: a total of 90 patients were audited based on standards drawn from different literatures recommendations. The administration of $100 \%$ oxygen, suctioning and debris removal and reversal given before extubation were attaining $100 \%$ of the audit standards. Extubation at the end of inspiration, initiation with reversals when the patient started to adequately breath and extubation of the patient when the patients can maintain saturation of $\geq 95 \%$ without oxygen source were attaining $60 \%, 60 \%$ and $66.6 \%$ respectively. However, interruption of the anesthetic drugs after confirmation of the start of breathing, ensuring of the patient raising of arms $\geq 10$ seconds from the operating table and head tilt $\geq 5$ seconds and extubation of patients in left lateral position were attaining below $50 \%$ of the standards.

Conclusion: most of the quality indicators of post anesthesia extubation practices were below the average standards. So training should be given for all anesthetists who will be involved in day to day anesthesia practices and regular re-auditing should be done to attain the given standards.

Keywords: extubation, general anesthesia, clinical audit
Volume II Issue 3 - 2019

\author{
Wubie Birlie Chekol, Debas Yaregal Melese, \\ Abrham Tarekegn \\ Department of Anesthesia, University of Gondar, Ethiopia
}

Correspondence: Wubie Birlie Chekol, Department of anesthesia, university of Gondar, Gondar, Ethiopia, Tel +251918200770, Email birliewubi@gmail.com

Received: December 12, 2019 | Published: December 27, 2019

\section{Introduction}

Endotracheal extubation is termed as the removal of an endotracheal tube from the trachea. It is a logical consequence of tracheal intubation. After extubation airway control is equally as important as securing the airway during anesthesia. This procedure is commonly done in operation rooms, post anesthesia care units and intensive care units. Endotracheal extubation is indicated when the clinical conditions that required airway protection with an endotracheal tube no longer needed. Endotracheal extubation is usually performed when patients are awake or have emerged from general anesthesia. ${ }^{1}$ Successful extubation should be the first priority for the anesthetist through checking the adequacy of breathing, verbal commands, full reversal of muscle relaxants and stabilizing of the vital signs. Safe extubation is very important for maintaining a patency of patient air way and avoiding post extubation hypoxemia. Successful extubation is defined as effective airway protection after removing the endotracheal tube and it is determined by effective cough reflex function and preserved mental status in the absence of airway obstruction. ${ }^{2}$
Before extubation the anesthetist should insure that there is adequate pain control established, adequate respiratory effort is present with minimal support, with $100 \%$ inspired oxygen delivered through the breathing circuit and Suction the patient's endotracheal tube with suction device. ${ }^{3}$

The occurrence of respiratory and cardiac complications after extubation is high, unless careful decisions are made. These complications include pulmonary aspiration, hypoxemia, cardiovascular stress and death. Extubation is contraindicated if patient does not have protective airway reflexes and if not maintaining adequate spontaneous respiration. Extubation is usually leads to increase in blood pressure and heart rate. Patients with severe cardio respiratory disorders, obese patients and patients who had experienced multiple intubation attempts are certainly the candidates for problematic extubation and eventual re-intubation. ${ }^{4-6}$

Most complications that will happened during extubation are preventable, so before performing extubation, the anesthetist must carefully prepare materials that needed to address reasonably 
happened complications..$^{7-9}$ Almost all tracheal intubations are done with consideration of subsequent extubation. Tracheal extubation in anesthesia practice is not only an important pass for patient recovery, but also a procedure that carries a considerable risk of complications. ${ }^{10,11}$ Extubation is associated with the risk of complications such as accumulated secretion above the endotracheal tube cuff, eventual atelectasis following a reduction in pulmonary volumes because of a lack of physiological positive end expiratory pressure and intra-tracheal suction. ${ }^{12}$ Respiratory complications after tracheal extubation are three times more common than complications occurring during tracheal intubation and induction of anesthesia. ${ }^{13}$

According to previous studies the incidence of post extubation respiratory adverse events were $4-5 \%$ and emergency tracheal reintubation was $0.19 \%$ and the major events were preventable if extubation is done in a safe manner. ${ }^{14-16}$
This audit mainly aimed to identify the gap between the current practices of endotracheal extubation with the different literatures recommendations, to decide the appropriate time for endotracheal extubation, to reduce unsuccessful extubation in daily anesthesia practices, to create emphasis in pre-established extubation plan and to minimize the possibility of complications related to extubation.

\section{Methods}

This clinical audit was conducted from January 1 to February 30; 2019.All patients who undergone surgery with general anesthesia in the study period were included. A data collection tools were prepared based on different literatures recommendations. Direct observations of the practical aspects of the anesthetists were used as a source of information (Table 1).

Table I Data collection tools

\begin{tabular}{llll}
\hline Data collection tools & Targets & Data sources & Evidences \\
\hline $\begin{array}{l}\text { Does the patient oxygenated with } 100 \% \text { oxygen prior to extubation? } \\
\text { Does the patient extubated in left lateral position }\end{array}$ & $100 \%$ & Direct observation & {$[17,17]$} \\
Does extubation done at the end of inspiration? & $100 \%$ & Direct observation & {$[17]$} \\
$\begin{array}{l}\text { Does patient can raise arms } \geq 10 \text { seconds from the operating table and head tilt } \geq 5 \\
\text { seconds before extubation? }\end{array}$ & $100 \%$ & Direct observation \\
$\begin{array}{l}\text { Does the air way suctioned carefully to remove the accumulated secretions and debris } \\
\text { before extubation? }\end{array}$ & $100 \%$ & Direct observation & {$[1]$} \\
$\begin{array}{l}\text { Does use of I mg/kg of } 2 \% \text { lidocaine sprayed down the endotracheal tube } 5 \text { minutes } \\
\text { before extubation? }\end{array}$ & $100 \%$ & Direct observation & {$[1,18]$} \\
$\begin{array}{l}\text { Does the patient reversed before extubation? } \\
\text { Does the patient extubated with saturation maintenance of } \geq 95 \% \text { without oxygen }\end{array}$ & $100 \%$ & Direct observation \\
source? \\
$\begin{array}{l}\text { Does the patient put with no anesthetic drug after confirmation of the start of } \\
\text { breathing after none depolarizing neuromuscular blocker? }\end{array}$ & $100 \%$ & Direct observation & {$[17,19]$}
\end{tabular}

\section{Results}

A total of 90 patients were audited based on the quality indicators of post anesthesia extubation. Prior to extubation $100 \%$ oxygen, suctioning and debris removal before extubation and reversal given before extubation were attaining $100 \%$ of the audit standards. However, blunting of the airway with lidocaine spray through the endotracheal tube before extubation was not done at all (Table 2).

Table 2 Responses of the Quality indicators for post anesthesia extubation

\begin{tabular}{|c|c|c|}
\hline \multirow[t]{2}{*}{ Quality indicators for post anesthesia extubation } & \multicolumn{2}{|c|}{ Responses (n (\%)) } \\
\hline & Yes & No \\
\hline Does the patient oxygenated with $100 \%$ oxygen prior to extubation? & $90(100)$ & $0(0)$ \\
\hline Does the patient extubated in left lateral position & $36(40)$ & $54(60)$ \\
\hline Does extubation done at the end of inspiration? & $54(60)$ & $36(40)$ \\
\hline
\end{tabular}


Table continue

Quality indicators for post anesthesia extubation

\begin{tabular}{|c|c|c|}
\hline & Yes & No \\
\hline $\begin{array}{l}\text { Does patient can raise arms } \geq 10 \text { seconds from the operating table and head tilt } \geq 5 \\
\text { seconds before extubation? }\end{array}$ & $18(20)$ & $72(80)$ \\
\hline $\begin{array}{l}\text { Does the air way suctioned carefully to remove the accumulated secretions and debris } \\
\text { before extubation? }\end{array}$ & $90(100)$ & $0(0)$ \\
\hline $\begin{array}{l}\text { Does use of I } \mathrm{mg} / \mathrm{kg} \text { of } 2 \% \text { lidocaine sprayed down the endotracheal tube } 5 \text { minutes } \\
\text { before extubation? }\end{array}$ & $0(0)$ & $90(100)$ \\
\hline Does the patient reversed before extubation? & $90(100)$ & $0(0)$ \\
\hline $\begin{array}{l}\text { Does the patient extubated with saturation maintenance of } \geq 95 \% \text { without oxygen } \\
\text { source? }\end{array}$ & $60(66.6)$ & $30(33.4)$ \\
\hline $\begin{array}{l}\text { Does the patient put with no anesthetic drugs after confirmation of the start of breathing } \\
\text { after non-depolarizing neuromuscular blocker? }\end{array}$ & $18(20)$ & $72(80)$ \\
\hline
\end{tabular}

\section{Discussion}

This audit mainly aimed in assessing the postextubation quality indicators; to avoid the residual effect of neuromuscular blockers, to alleviate aspiration risk, to reduce the surging of blood pressure and heart rate, to avoid patient being hypoxemia and to balance the patients comfort and safe transfer to the recovery wards. According to this clinical audit, suctioning and removal of debris before extubation, $100 \%$ oxygen before extubation and giving of reversal before extubation were attaining $100 \%$ of the audit standards. On the same hand, previous studies also recommended to use $100 \%$ of oxygen before extubation so as to reduce the incidence of early hypoxemia during transfer period and in post anesthesia care unit. ${ }^{17,18}$ Inadequate reversal of the non depolarizing neuromuscular blockers will contribute for postextubation hypoxemia. To reduce such complications it is must to reverse patients who were on non depolarizing neuromuscular blockers. ${ }^{17}$ Pulmonary aspiration mainly happened during extubation time when compared to intubation time. To alleviate such complications researchers advised to suck secretions and debris adequately. ${ }^{19}$

As per our audit standards, patient extubation with saturation maintenance of $\geq 95 \%$ without oxygen source was $66.6 \%$ and extubation done at the end of inspiration was $60 \%$.Even though, these quality indicators were above the average of the audit standards, it needs some improvements to attain the $100 \%$ of the audit standards. According to different literatures recommendations since glottis closure increased during inspiration, extubation should be done at the end of inspiration so as to prevent trauma and laryngospasm. ${ }^{20}$ Also previous studies explained that oxygen supplementation is mandatory if patient saturation is below $94 \% .^{21}$

Based on our clinical audit standards lidocaine spray through the endotracheal tube before 5 minutes, discontinuing of the anesthetic agents with confirmation of the start of breathing after nondepolarizing neuromuscular blockers and extubation with left lateral position were attaining below the average value of the audit standards. However previous studies recommended to extubate patients at the left lateral position so as to maintain the patency of the airway and to prevent from aspiration risks. ${ }^{22}$ Additionally different literatures explained that there is high incidence of surging of the hemodynamic parameters such as blood pressure and heart rate with a $10-30 \%$ which lasted 5-15 minutes. To minimize this $2 \%$ lidocaine spray with $1 \mathrm{mg} / \mathrm{kg}$ before 5 minute was used effectively. ${ }^{20,22,24}$

\section{Conclusion}

Most of the quality indicators of post anesthesia extubation practices were below the average standards. So regular training should be given for students and all anesthetists who will be involved in day to day anesthesia practices and regular re auditing should be done to attain the given standards.

\section{Financial support and sponsorship}

Nil.

\section{Conflicts of interest}

There are no conflicts of interest.

\section{References}

1. Ortega R,Connor C,Rodriguez G, etal.Endotracheal Extubation.N Engl J Med. 2014;370:1266-1268.

2. Miller KA, Harkin CP, Bailey PL. Postoperative tracheal extubation. AnesthAnalg. 1995;80(1):149-172.

3. Peteford AJ. Extubation after anesthesia:systemic review. Update in Anaesthesia.2011.

4. Artime CA,Hagberg CA.Tracheal Extubation.Respir Care.2014;59(6):9911005.

5. Jayrajh SA.Postoperative Tracheal Extubation: Current Controversies. $2013 ; 20$.

6. Howie WO, Dutton RP. Implementation of an evidence-based extubation checklist to reduce extubation failure in patients with trauma: a pilot study. AANA J. 2012;80(3):179-184

7. Karmarkar S, Varshney S. Tracheal extubation. ContinEducAnaesthCrit Care Pain. 2008;8(6):214-220.

8. Asai T, Koga K, Vaughan RS. Respiratory complications associated with tracheal intubation and extubation. Br J Anaesthesia. 1998; 80(6):767-775.

9. Vaughan RS. Extubation - yesterday and today. Anaesthesia. 2003;58(10):945-950. 
10. Miller KA, Harkin CP, Bailey PL. Postoperative tracheal extubation AnesthAnalg. 1995;80(1):149-172.

11. Ng A, Smith G. Gastrooesophageal reflux and aspiration of gastric contents in anesthetic practice. AnesthAnalg. 2001;93(2):494-513.

12. Olympio MA, Youngblood BL, James RL. Emergence from anaesthesia in the prone vs. supine position in patients undergoing lumbar surgery. Anesthesiology. 2000;93(4):959-963.

13. Magnusson L, Spahn DR. New concepts of atelectasis during general anaesthesia. Br J Anaesthesia. 2003;91(1):61-72.

14. Yousefshahi F, Barkhordari K, Movafegh A, et al. A New Method for Extubation: Comparison between Conventional and New Methods. J TehUniv Heart Ctr. 2012;7(3):121-127.
15. Ruth HS, Haugen FE, Grove DD. Anesthesia study commission. JAMA.1947;135:881-884.

16. Hovi-Viander M. Death associated with anaesthesia in Finland.Br J Anaesth. 1980;52(5):483-489.

17. Swati K, V Seema. Tracheal extubation. Continuing Education in Anaesthesia. Critical Care \& Pain. 2008;8(6).

18. Carl F, FP Henry, L John. The Effects of Intracuff Lidocaine on Endotracheal-Tube-Induced Emergence Phenomena After General Anesthesia. AnesthAnalg. 2000;9(1):201-205.

19. Benoît Z, Wicky S, Fischer JF, et al. The Effect of Increased FIO2 Before Tracheal Extubation on Postoperative Atelectasis. AnesthAnalg. 2002. 95(6):1777-1781. 